\title{
Subvalvular Aortic Stenosis
}

National Cancer Institute

\section{Source}

National Cancer Institute. Subvalvular Aortic Stenosis. NCI Thesaurus. Code C85172.

An aortic stenosis caused by fibromuscular stenosis or hypertrophic cardiomyopathy. It

may be associated with congenital heart defects. 